\title{
Welcoming families by school - important factors for cooperation between school and family to prevent violence among students.
}

\author{
Mr.sc. Vlora Sylaj \\ University of Prishtina, Department of Pedagogy, Prishtina, Kosovo. \\ Email: vlora.sylaj@gmail.com
}

DOI: $10.2478 /$ seeur-2013-0007

\begin{abstract}
This article aims to contribute to the growing interest and consideration for the importance of the welcoming family of schools to prevent violence among students.

This study reflects upon the importance of qualitative collaboration, namely to enrich the public opinion with the valuable information about the cooperation between school and family. The purpose of this article is to ascertain whether it affects the level of contacts between school and family for preventing violence among students by family welcoming at school.This study used quantitative method and aims to find answers to the following questions: What are the forms of violence among students in school? What are its dimensions? What are the reasons? What impact has the use of violence? What attitudes are being held towards violence? Are there school programs that deal directly with the study, prevention, rehabilitation? At what level is welcomed by the family of schools for prevention of violence among students. Research hypothesis: The level of contacts between the school and families affected by the welcoming family at school. We have included 400 teachers and 400 parents from rural areas in this study, as well as 300 teachers and 300 parents of fourth classes' from the urban areas. Were made 98 interviews with parents and 97 with the teachers. 97 pupils are involved in focus groop. They come from the various city schools in Kosovo. Systematic sample was randomly selected, and we have compiled the questionnaire.
\end{abstract}


A team of pedagogues, who have been previously trained to use this questionnaire, took attitudes of both subjects. Data were analyzed by SPSS 20 program. The study has reached some findings and conclusions. Participants' responses indicate that the level of contact between the school and families for preventing violence among students is affected by the factor family welcoming at school.

Key words: school, family, cooperation, welcoming families by the school, violence.

\section{Introduction}

In the past, the school was less involved in family facilitation irrespective of their integral and strategic position in community (Weiss et al., 2005). Nowadays, school-family cooperation is current and important for both teachers and family and community, especially in this time when we know that school itself cannot succeed alone with students and cannot overcome problems, including the prevention of violence among students. Therefore, the cooperation with family is a necessity.

Significant factors for cooperation between school and family for preventing the violence among students include communication, family information, sharing tasks and responsibilities, decision making, supporting student achievement, trust between school and family and vice versa, previous family experience with school, and welcoming family by school. Welcoming should be the first to precede the school-family cooperation for preventing the violence among students. This implies that when the family is at school it needs to feel part of it, to see the school as their place, "where they belong", not to discriminate the families - all of them to be treated equally irrespective of their intellectual, cultural, or social background etc. School should have a certain place for meetings with families. To feel not welcomed by school poses various obstacles to school-family cooperation. In this article we will focus in stating the level of welcoming of families at school by school and its relation to the level of contacts between school and family for preventing the violence among students.

\section{Survey's Methodology}

Operational definitions - Family is a group of individuals related by blood, marriage or cohabitation approval. Family should be more involved and participate in school. School is the educational institution in which the organized activity of upbringing and education of the young generation takes place. Establishing the highest level of school role through cooperation with the family. Cooperation between school and family are activities and cooperation agreements between them to achieve common goals. Welcoming families by the school - this means that when the family is at school feel that's part of it, to see school as a place that they "belongs" not forthcoming from the family discrimination - all are treated equally regardless of their level of education, cultural, social, etc.., and schools possess a special place for the meeting with the family. Violence among students is an expression, behaviour or action of a pupil or more, in one or more students.

The aim of the study - The purpose of this study is to determine the level of effect of welcoming families by school for cooperation in order to prevent violence among students at school. 
Study Questions: Does the family welcome from the school level meetings between school and family to prevent violence among students? Are there significant differences on this issue between the family and school environment when families comes from urban and rural areas?

Research hypothesis: The level of meetings between school and family to prevent the violence among students is influenced by welcoming the family by the school.

The importance of the study: This study is important because it affects the welcoming family by school and it establishes the contacts with the family. Also, note that the relationship between these variables is the same in urban and rural areas.

Limitations of the study. This study may be limited by the following factors:

- Teachers may be cautious in providing information in collaboration with the family.

- Restrictions on giving honest responses may also encounter family.

Population and sample- The population of this research are all teachers and parents of elementary schools in Kosovo. Population is determined numerically and the largest number of pupils comes from rural areas. Since it is the large population to study the problem, we have defined the version of the study - sampling was done through systematic random selection. The sample included 300 teachers and 300 parents of fourth grade school from urban areas in Kosovo, and 400 teachers and 400 parents of school fourth grade from rural areas in seven regions of Kosovo. Were made 98 interviews with parents and 97 with teachers. 97 pupils are involved in focus groop.

Instrument applied. We have applied research assessment to determine the welcoming family by school from the school and the level of contacts between school and family. We applied comparative research for the comparison of differences in school and family attitudes and cooperation between them.

Applied instrument is a questionnaire for parents and teachers, which consists of questions through which we discover how the success of students is supported by the school. The questionnaire consists of five scales: "strongly agree", "agree", and "undecided", 'disagree ", and "strongly agree". Answers about violence among students are taken through the interview and focus group.

\section{Literature review}

The so far formal cooperation between school and family for preventing the violence among students in Kosovo made this phenomenon to still be present. There are different factors, including the fact whether parents really feel welcomed at school from school to prevent this phenomenon. And certainly the situation is not the same in all schools. The reason that some schools have better cooperation than others, among others is the welcoming that school offers to the family. Inadequate reception of families at school makes parents to be part of it or to be out of school. A study shows that $75 \%$ of teachers want the parents to be involved at school and 74\% of parents want to be involved at school (Berger, 2000). In another project, it was found that $86.8 \%$ of teachers and $92.1 \%$ of 2.300 school directors think that teachers need trainings for involvement of parents at school (Williams, 1992). Meanwhile, the higher involvement of parents or families in school for preventing the violence among students makes them feel welcomed, as if school keeps doors open for them. Berger, in her studies shows that the family feels welcomed at school if school has staff that makes the visitors feel welcomed (Berger, 2000). School has the task and responsibility to invite family for cooperation in order to prevent the violence among students, but not all the 
parents experience equally the notification for a meeting at school. "Some parents experience joy for their future visit at school, but others are afraid and in a way shocked from the notification for the coming meeting at school." (Kreso, 2004). Also, at school parents come with different experiences from their schools and with a different level of their pedagogical culture, then "if school and teachers cannot know, understand and respect the diversity of feeling of parents towards school, school's experience, that has a better chance for success for first steps of partnership" (Kreso, 2004), and such a recognition is achieved through welcoming.

Welcoming family from school is a complex issue. This complexity is manifested with the fact that not all the parents are equally treated by school "elimination of ignorance, discrimination in democratic schools is a way that all participate in a meaningful way before school meets all the future challenges" (Berger, 2000). While, Cooleys demands that family should not see disregard and disrespect. He in his studies shows the fact that how we see ourselves depends on our perceptions how others see us. And, this fact has three phases: reflection (parents watch themselves in the mirror), interpretation of reflection (How they interpret what they see) and the feelings of pride and shame. If in the second step parents reflect positively, in the next step they feel pride and they will work with the school for their children's benefits. If they see disregard and disrespect it will be really hard for them to work as parents (Cooleys, 1964).

\section{Results and discussion}

Presentation of the results and their discussion is divided into two parts. In the first part we are informed about forms of violence among students, the attitudes towards the violence, the reasons for use of violence, existence or non-existence of programs that deal directly with the study, prevention and rehabilitation. In the second part we are acquainted with the level of family confidence in the school in cooperation for prevention of violence among students.

Physical violence among students in school. Findings show that forms of physical violence among students, declared by students, teachers and parents are kicking, pushing, hair pulling, hitting with objects in the body, hitting with fist, etc. Very common form of violence among students is fighting with fists with $12.47 \%$. Usually they start with pushing and continue to fist fighting. The data shows that $35 \%$ of interviewed students experienced pushing by other students. $5,15 \%$ hair pulling, kicking 7,54 \%. The leading form of violence is pushing "it also happens sometimes in the form of ridicule, but a case of pushing for "fun" a friend resulted with a fall from stairs and her arm was badly hurt" (student). The study also reveals hitting with various objects as a form of violence among students, the extent of this form of the violence are from 7.5 to $9.24 \%$. Of all respondents $65 \%$ of students believe that physical violence among students is used more than psychological violence. The same attitude is among teachers and the family. The study reveals that violence is significantly more present among male students. Findings suggest greater attention to this issue.

Psychological violence among students in school. Reporters of the violence - subjects stated that the most common forms of violence among students is bullying, followed by insults, jealousy each other, threats, using insulting nicknames. It seems that psychological violence among students in school is no less intense. Among these forms insults lead with 53 $\%$. Various threats by $22.8 \%$, using insulting nicknames $36.87 \%$.

The reasons for the use of violence among students are various. The reason which leads to the interview with the family and the school is the ego of students. While students' reasons which lead out to be $42.7 \%$ is associated with the philosophy that students do not respect the 
standards of proper behavior - right, and $17.88 \%$ view their discipline means "doing better" for some students.

Not large percentage but is also evident is "the jealous on grades" as the reason for use of violence by students. Based on student's reports, this is a manifestation of violence among students "because we have cases where only a few are invited to engagement in school programs and activities etc. . " (Teacher). A friend of ours is not in all subjects excellent, but teachers are based in other grades to put their grade, she does not deserve all A's " (student). Or, statement of two other students "Teachers usually ask at the beginning of the semester students supposedly better, then those students fall asleep and remain the best again."'One other issue in schools is that students are more told about their rights and little about their responsibilities that they have. This attitude is protected by $34 \%$ of teachers. They estimate that this fact is an element of "tolerating" the violence among them. A teacher who is just to be retired says that he doesn't dare to raise his voice against students, if I do that, students abruptly indicate that I have no right to raise my voice. In the past it was different".

Attitudes to physical and psychological violence among students. The vast majority of respondents think that physical violence is more harmful than psychological violence. Saying that "Who asks for it finds it" is widespread among students. Although there is some awareness that violence has negative consequences, information about the consequences of physical violence and particularly what is psychological violence are rather limited and unspecific.

Consequences. The study reveals that the consequences of experiencing violence among students are more of a psychological nature. Based on the findings, they are emotional realm of students, which is manifested in their uncertainty, where $17.82 \%$ of them claim to have had the idea of dropout. It means that we have "damage" of the emotional sphere as a result of experienced violence. The first event is jealousy "breaking with each other", which will undoubtedly leave traces. Then, intervention in the case of other friends - creating groups and couples. While there are few cases of closing itself." It is a friend which is usually ignored by classmates, and her family have sent her to another school" (student). It is disturbing fact that students and family don't have enough information about the consequences of psychological violence.

During the interview it appears that some forms of violence among students is not reported to the family and the school. Then it appears that there we might have major consequences of violence among students, which can be repeated as conflict or harassment and revenge will remain in the students head for a long time, thus preventing his/hers activity. Among some cases a mother confesses that: "My son was physically harassed by another student, the conflict which has lasted a while until one day his mother was accidentally informed by a mother of his friend." From this statement and other similar statements, it appears that not all cases are known/reported to the school and family. Of course this depends a lot from the seriousness of the school in handling cases of violence.

Are there programs or not that deals with prevention, research, rehabilitation? Violence among students in school is prohibited by the law, but the study found that students lack information about the consequences of violence among students. School did not meet at this point its task. In one of the capital's schools teachers justify it with the fact that some of the information listed in billboards in the hallway, this action is not sufficient. Findings suggest greater attention to this issue. The study findings show that schools and families cooperate unfairly in case of violence among students. School collaborates with the family because of the success but not in terms of preventing violence. This finding is based on the fact that cases of violence are resolved between family and school through the bargain. This reveals that the conflicts between students are not justly treated in depth. These cases have 
been resolved after the violence. The study interviews reveal that the school has no programs to address violence among students. Then it appears that problems are solved unprofessionally. And not based on the cooperation for prevention in our schools do not figure, even though we all know the popular saying that it is better to prevent than to cure it.

In this part of the article it will be presented followed by a discussion of the family the level of trust that makes schools work to prevent violence among students and the relationship between the family trust in the work of school prevention violence among students and contacts of the number of family with school for the prevention of violence among school students.

The relationship between family welcoming in the work of school in violence prevention among students and the number of family contacts for the prevention of school violence among students in schools is explored through Pirsons coefficient. Statistical tests were carried out in advance whether the distribution is normal.

Groups of questions measuring instrument indicate an alpha coefficient of .962 Kotrabah, which is a high reliability.

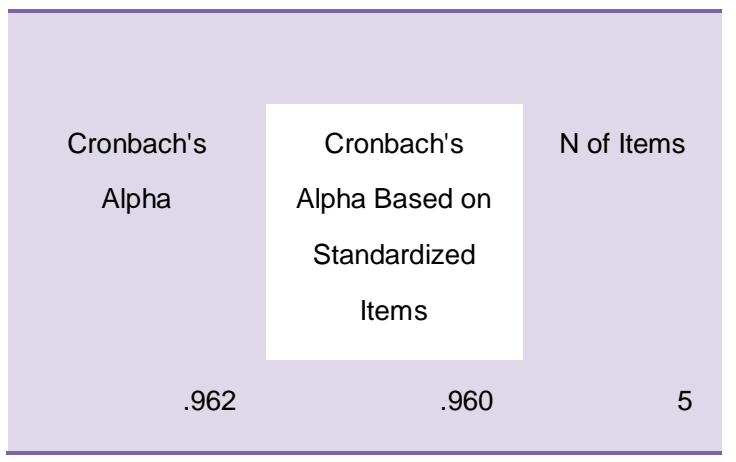

Based on the statistical results of Table 1 we understand that teachers of schools from urban areas in Kosovo consider that welcoming the family by school for prevention of violence among students is high. A big difference is between "medium" and "high" level. We don't have any teachers that consider that welcoming the parents by school is in a low level, while only $20 \%$ of them consider this as a medium level. The results on the table show clearly that the teachers from urban areas consider very high their welcoming that they offer to the families for prevention of violence among students at school.

\begin{tabular}{llrrrr}
\hline & & Frequency & Percent & Valid Percent & \multicolumn{1}{c}{$\begin{array}{c}\text { Cumulative } \\
\text { Percent }\end{array}$} \\
\multirow{3}{*}{ Valid } & low & 60 & 20.0 & 20.0 & 20.0 \\
\cline { 2 - 5 } & medium & 240 & 80.0 & 80.0 & 100.0 \\
\hline
\end{tabular}

Table 1. The attitudes of students from urban areas for their welcoming offered to the family.

Meanwhile, the study in data from Table 2 shows the strong correlation between welcoming the family from urban area by school from that area and the level of contacts between school and family for preventing the violence among students of that school. It was 
found that the welcoming of family at school and the level of contacts between school and family has a high correlation with statistical significance $(r=.078, p=.005, n=300)$. We can state that the level of meetings between school from urban area and family increases with the increase of level of welcoming family from school.

\begin{tabular}{llrr}
\hline \multirow{3}{*}{ Welcoming } & & Welcoming & Nr. Meetings \\
\cline { 2 - 3 } & Pearson Correlation & 1 & .078 \\
\cline { 2 - 3 } Nr. Meetings & Sig. (2-tailed) & & .005 \\
& $\mathrm{~N}$ & 300 & 300 \\
& Pearson Correlation & .078 & 1 \\
\cline { 2 - 4 } & Sig. (2-tailed) & .005 & \\
& $\mathrm{~N}$ & 300 & 300 \\
\hline
\end{tabular}

Table 2. Welcoming the family by school and the level of meetings of students from urban areas with family.

The study of the data from Table 3 shows us that the attitudes of teachers from rural areas are those that show that welcoming is a significant factor in the level of contacts between school and family to prevent the violence among students. $99 \%$ of teachers have that attitude.

\begin{tabular}{llrrrr}
\hline & & Frequency & Percent & Valid Percent & \multicolumn{1}{c}{$\begin{array}{c}\text { Cumulative } \\
\text { Percent }\end{array}$} \\
Valid & high & 400 & 99.3 & 100.0 & 100.0 \\
Missing & System & 3 & .7 & & \\
Total & & 403 & 100.0 & & \\
\hline
\end{tabular}

Table 3. The attitudes of teachers from rural areas for their welcoming offered to the families.

Correlation between welcoming the family by school in the rural areas and the level of contacts between school and family to prevent the violence among students is considered high also and statistically significant $(\mathrm{r}=.687, \mathrm{p}=.003, \mathrm{n}=400)$.

These data make it clear to us that the level of contacts between rural schools and family on prevention of violence among students, among else, is affected by welcoming of family by school.

\begin{tabular}{l|lrr}
\hline \multirow{3}{*}{ welcoming } & \multicolumn{1}{c}{ Welcoming } & Nr. Meetings \\
\cline { 2 - 3 } & Pearson Correlation & 1 & .687 \\
\cline { 2 - 3 } & Sig. (2-tailed) & & .003 \\
\cline { 2 - 3 } Nr. Meetings & $\mathrm{N}$ & 400 & 400 \\
& Pearson Correlation & .687 & 1 \\
\cline { 2 - 4 } & Sig. (2-tailed) & .003 & \\
& & & 300 \\
\hline
\end{tabular}

Table 4. The welcoming of family from school and the level of meetings of teachers from rural areas with family. 
Data on Table 5 show the percentage of parents of urban schools that are satisfied with their welcoming by school. They consider it as high. 97\% of parents express such an attitude. Only $3 \%$ of them consider it as average. Meanwhile, it is observed that there are parents of urban schools who are not satisfied how they are welcomed by school. On the other hand, it can be observed that that welcoming as a successful factor of cooperation between school and family for prevention of violence among students affects the level of contacts among these two cooperating entities. Urban parents are convincing in this regard.

\begin{tabular}{llrrrr}
\hline & & Frequency & Percent & Valid Percent & $\begin{array}{c}\text { Cumulative } \\
\text { Percent }\end{array}$ \\
\multirow{2}{*}{ Valid } & medium & & & .3 & .3 \\
& high & 299 & 97.8 & 99.7 & 100.0 \\
& Total & 300 & 96.2 & 100.0 & \\
Missing & System & 12 & 3.8 & & \\
Total & & 312 & 100.0 & & \\
\hline
\end{tabular}

Table 5. The attitudes of parents from urban areas for their welcoming offered to school.

Table 6 shows that the level of correlation between welcoming of urban parents and the level of their contacts with the school is high, and there is a strong positive linear correlation, which is also statistically significant $(r=.543, p=.000, n=300)$. According to attitudes of urban parents, welcoming that school implements with parents increases the level of contacts among them for prevention of violence among students.

\begin{tabular}{llrr}
\hline \multirow{3}{*}{ Welcoming } & \multicolumn{2}{c}{ Welcoming } & \multicolumn{2}{c}{ Nr. Meetings } \\
& Pearson Correlation & 1 & $.543^{\text {** }}$ \\
& Sig. (2-tailed) & & .000 \\
\cline { 2 - 3 } Nr. Meetings & N & 300 & 300 \\
& Pearson Correlation & $.543^{* *}$ & 1 \\
& Sig. (2-tailed) & .000 & 300 \\
\hline
\end{tabular}

Table 6. The welcoming of family by school and the level of meetings of parents from urban areas with teachers.

Data from Table 7 make it clear to us that rural parents are welcomed at school. In total, 97\% of parents state that they feel welcomed at school. This shows a high rate of welcoming of rural families at school. 


\begin{tabular}{rlrrrr}
\hline & & Frequency & Percent & Valid Percent & \multicolumn{2}{c}{$\begin{array}{c}\text { Cumulative } \\
\text { Percent }\end{array}$} \\
\multirow{3}{*}{ Valid } & & & & 3.0 \\
& medium & 12 & 3.0 & 3.0 & 100.0 \\
\hline & high & 388 & 97.0 & 97.0 & \\
\hline
\end{tabular}

Table 7. The attitudes of parents from rural areas for their welcoming offered to the families.

The correlation between the level of contacts between the school and family and rural family is also found to be strong, as is seen in Table 8 . The study shows, as observed in the final result $(\mathrm{r}=.076, \mathrm{p}=003, \mathrm{n}=400)$, that the correlation between welcoming of families by rural school teachers and the level of contacts between the school and family for prevention of violence among students is high and statistically significant.

\begin{tabular}{l|lrr}
\hline \multirow{3}{*}{ welcoming } & & Welcoming & Nr. Meetings \\
& Pearson Correlation & 1 & .076 \\
& Sig. (2-tailed) & & .003 \\
\cline { 2 - 3 } Nr. Meetings & $\mathrm{N}$ & 400 & 400 \\
& Pearson Correlation & .076 & 1 \\
\cline { 2 - 4 } & Sig. (2-tailed) & .000 & \\
& $\mathrm{~N}$ & 400 & 400 \\
\hline
\end{tabular}

Table 8. The welcoming of family from school and the level of meetings of parents from rural areas with teachers

\section{Conclusions and recommendations}

Recommendation is addressed to the school which is to inform family and students about the consequences of violence among students - penalties. Research shows that families and students are not informed in this regard, but, as we said above even consider only information that will serve as an element of prevention of violence among students.

The second recommendation that emerged from the study is that school must have adequate programs to adress violence among students. In addition, it must have programs for preventing violence among students, which our school is lacking.

The inclusion of psychological services in primary schools is a must which among other activities treats the issue of violence among students. There are a very small number of schools that have this essential service in this matter.

The statistical data indicate that urban and rural school teachers consider welcoming of the family by school to be at high level. The differences are minor among them on this issue. Also, the parents of both rural and urban areas consider that they are welcomed at school, and differences among them are minor too; rural area parents show that the level of welcoming at 
school is slightly higher. Regarding correlation between the level of contacts between the school and family for prevention of violence among students at school, we state that teachers from both areas consider the relationship as strong which means that indeed the higher the welcome of family by school the more frequent are the meetings between them and the school for prevention of violence among students. Also, for parents of both areas, the study shows a strong correlation between the welcoming and level of contacts between the family and school, therefore the high level of welcome conditions the level of contacts between the family and school for prevention of violence among students.

In the space provided in the questionnaire for "Your eventual comments on welcoming", parents expressed their concern about the fact that there is no special room for meetings with teachers at school. The meetings between parents and teachers take place in school halls or in its yards besides collective meetings, which are envisioned twice per term. We might raise the question whether these meetings between family and school held in these areas are productive or formal? This question is addressed in particular to educational leadership institutions, and we recommend them to provide a special location for meetings for family and school to take place at every school. 


\section{References}

1. Berger,E.H. (2000), Parents as partnets in education: Families and school working together.

2. Bohan, $M$ \& Priscilla, $M(2002)$, Harvard Family Research Project.

3. Cooley,H.C. (1964). Humah natyre and the social order. New York.

4. Davies, D. (1993). Benefits and barriers to parent involvement: From Portugal to Boston

5. Epstein,J.L (2001). School, family and community partnership: helping educators and improving school. Boulder,CO.

6. Evans, L.(2002), Haw to help yor child succeed at school,New York

7. Grup autorësh .(2001), Better parenting iniatives.

8. Koliqi, Hajrullah. (2000). Mbijetesa e Universitetit të Prishtinës, Prishtinë.

9. Kreso, A. P . (2004) Koordinate obiteljskog odgoja, Sarajevo. New Jersey: Merrill Publishing Company.

10. Zuna, A..bashkëautorët. (2009). Partneriteti shkollë-familje-komunitet. Prishtinë.

11. Williams, D. L. (1992) . Parental involvement teacher preparation.

12. World report on violence and health, Etienne G. Krug, Linda L. Dahlberg, James A. Mercy, Anthony B. Zwi and Rafael Lozano, World Health Organization, Geneva, 2002. 